The samples were then mounted on aluminum stubs and sputtercoated with gold.

For comparison, tissue-culture cells without spirochetes were similarly prepared. Also, spirochetes grown in BSK II alone were gently drawn down on a $0.2 \mu \mathrm{m}$ millipore filter and the filter was processed for scanning electron microscopy as above (figure 1A).

In each instance, spirochetes could be seen attached to most (figure 1B), but not all, of the cells grown in tissue culture. Higher magnification revealed that the spirochetes usually appeared as intertwined pairs at the host cell surface (figure $1 C$ ), and they were easily distinguished from the surface features of cultured cells that were not inoculated with spirochetes (figure 1D). We did not observe the spirochetes associated with small round bodies on the cell surface as reported with the spirochete-tick cell cultures [7]. We have established conditions that allow the B. burgdorferi spirochete to grow and attach to mammalian cells in vitro. This is the first step in the design of experiments for studying the parameters of attachment and the mechanisms of spirochete pathogenicity in mammalian cells.

Karim E. Hechemy, William A. Samsonoff, MaRy McKee, Joseph M. Guttman Wadsworth Center for Laboratories and Research, New York State Department of Health, Albany

\author{
References \\ 1. Christensen GD, Simpson WA, Beachy EH. Microbial adherence in \\ infection. In: Mandell GL, Douglas RG, Bennett XX, eds. Princi-
}

ples and practices of infectious diseases. New York: John Wiley \& Sons, 1985:6-23

2. Steere AC, Malawista SE, Bartenhagen NH, Spieler PN, Newman JH, Rahn DW, Hutchinson GJ, Green J, Snydman DR, Taylor E. The clinical spectrum and treatment of Lyme disease. Yale J Biol Med 1984;57:453-456

3. Burgdorfer W, Barbour AG, Hayes SF, Benach JL, Grunwaldt E, Davis JP. Lyme disease-a tick-borne spirochetosis? Science 1982; 216:1317-1319

4. Benach JL, Fleit HB, Habicht GS, Coleman JL, Bosler EM, Lane BP. Interactions of phagocytes with the Lyme disease spirochete: role of the Fc receptor. J Infect Dis 1984;150:497-507

5. Fumarola D, Cedola MC, Guanti G, Matsuura A, Uede T, Jirillo E. Adherence of Lyme disease spirochetes to rat lymphocytes. Zentralbl Bakteriol Mikrobiol Hyg [A] 1986;263:146-150

6. Peterson PK, Clawson CC, Lee DA, Garlich DJ, Quie PG, Johnson RC. Human phagocyte interactions with the Lyme disease spirochete. Infect Immun 1984;46:608-611

7. Kurtti TJ, Munderloh UG, Ahlstrand GG, Johnson RC. Borrelia burgdorferi in tick cell culture: growth and cellular adherence. J Med Entomol 1988;25:256-261

8. Benach JL, Coleman JL, Garcia-Mono JL, Deponte PC. Biological activity of Borrelia burgdorferi antigens. In: Benach JL, Bosler EM, eds. Lyme disease and related disorders. New York: Ann NY Acad Sci 1988;539:115-125

9. Madin SH, Darby NB Jr. Established kidney cell lines of normal adult bovine and ovine origin. Proc Soc Exp Biol Med 1958;98:574-576

10. Barbour AG. Isolation and cultivation of Lyme disease spirochetes. Yale J Biol Med 1984;57:521-555

THE JOURNAL OF INFECTIOUS DISEASES • VOL. 159, NO. 4 - APRIL 1989

(C) 1989 by The University of Chicago. All rights reserved. 0022-1899/89/5904-0042\$01.00

\section{Single-Dose Therapy for Oral Candidiasis with Fluconazole in HIV-Infected Adults: A Pilot Study}

Colleagues - Oral candidiasis is a common problem in neoplastic diseases, after prolonged antibiotic therapy, or in the aged, debilitated patient, but most cases are now seen in human immunodeficiency virus (HIV)-infected patients [1, 2]. In this setting, the infection is especially difficult to treat: topical antifungals are unpalatable, only partially effective, and relapses after treatment are generally observed. Systemic ketoconazole represents an efficient alternative, but hepatic toxicity [3] and the possibility of drug interaction with other medications frequently taken by these patients, like zidovudine, are of concern.

Fluconazole, (Pfizer, Zurich) is a novel bis-triazole antifungal agent exhibiting the following favorable pharmacokinetic properties: ( $I$ ) good absorption after oral administration $(85 \%$ bioavail-

This study was approved by the Research Ethics Committee of the Department of Internal Medicine at the Centre Hospitalier Universitaire Vaudois, Lausanne, and written informed consent was obtained from all subjects who received fluconazole.

Fluconazole was supplied by Pfizer, Fluelastrasse 7, 8048 Zurich, Switzerland.

Please address requests for reprints to Dr. M. P. Glauser, Division of Infectious Diseases, Centre Hospitalier Universitaire Vaudois, 1011 Lausanne, Switzerland. ability), (2) long plasma half-life ( $30 \mathrm{~h}),(3)$ low-plasma protein binding $(11 \%)$ with a rapid distribution in tissue fluids such as saliva, and (4) predominantly renal excretion $(60 \%)$ [4]. Preliminary experience in 95 patients with oropharyngeal candidiasis showed the drug was effective and well tolerated when given as a $50 \mathrm{mg}$ capsule once daily for a median period of $9 \mathrm{~d}$ [5]. However, the above-mentioned pharmacokinetic properties suggest that a single-dose treatment could be effective. We tested this hypothesis in an open, noncomparative study in HIV-infected adults presenting with oral candidiasis.

From 1 October 1987, all HIV-positive adults presenting at our institution with oral candidiasis were proposed a single oral dose of $150 \mathrm{mg}$ fluconazole as sole treatment. Patients with mouth symptoms (pain, burning, and dryness) and characteristic signs (raised confluent white patches on a hyperemic base) were included if the swab culture of the lesions showed $\geqslant 10$ Candida colonies after inoculation on a whole Sabouraud agar plate at bedside.

Eligible patients took a $150 \mathrm{mg}$ fluconazole capsule under direct medical supervision and were seen again on days 4,7 , and 14-21 and then once a month (within the framework of an ongoing AIDS cohort study). The culture was repeated on days 7 and 14-21. The clinical response was defined by the total disappearance of signs and symptoms, and the microbiologic response by the disappearance of Candida on culture, or a drop of two grades or more on a four-grade semiquantitative culture scale (table 1). 
Table 1. Clinical and microbiological evolution.

\begin{tabular}{|c|c|c|c|c|c|}
\hline $\begin{array}{l}\text { Patient (no. } \\
\text { previous epi- }\end{array}$ & & & Day & $14-21$ & Day 42 \\
\hline candidiasis & Day 0 & Day 7 & Clinical & & Clinical \\
\hline within $6 \mathrm{mo}$ ) & Culture* & Culture* & relapse & Culture* & relapse \\
\hline $1(2)$ & 4 & 1 & no & 2 & no \\
\hline 2 & 4 & 0 & yes & 3 & ND \\
\hline $3(6)$ & 3 & 0 & yes & 3 & ND \\
\hline 4 & 3 & 0 & no & 3 & no \\
\hline $5(2)$ & 4 & $4^{\dagger}$ & ND & ND & ND \\
\hline 6 & 4 & 2 & no & 2 & no \\
\hline $7(5)$ & 3 & 0 & no & 3 & no \\
\hline 8 & 3 & 0 & yes & 3 & ND \\
\hline $9(1)$ & 3 & 1 & no & 3 & yes \\
\hline 10 & 3 & 0 & no & 0 & no \\
\hline 11 & 4 & 0 & no & 3 & no \\
\hline $12 \ddagger$ & 3 & 0 & & & \\
\hline $13(7)$ & 2 & 1 & yes & 3 & ND \\
\hline $14 \ddagger$ & 3 & 3 & no & 3 & \\
\hline 15 & 3 & 2 & no & 1 & no \\
\hline $16(1)$ & 3 & $\mathbf{0}$ & no & 0 & yes \\
\hline 17 & 4 & 0 & no & 1 & no \\
\hline $18(3)$ & 3 & 0 & no & 2 & yes \\
\hline $19(3)$ & 3 & 0 & yes & 3 & ND \\
\hline 20 & 3 & 0 & no & 2 & no \\
\hline 21 & 4 & 1 & no & 1 & no \\
\hline 22 & 3 & 0 & no & 0 & yes \\
\hline 23 & 3 & 1 & no & 1 & no \\
\hline
\end{tabular}

NOTE. No patients had clinical relapse on day 4. ND $=$ no analysis after first relapse.

* 0 = no growth, 1 = 1-9 Candida colonies, $2=10-19$ colonies, $3=\geqslant 20$ colonies, $4=$ confluent growth.

$\dagger$ Patient 5 had clinical relapse on day 7 .

$\ddagger$ Died during study period.

We describe data from the first 31 patients. Three patients refused the protocol. One patient was excluded because she had pruritus and urticaria while receiving ketoconazole for a previous episode, which recurred with a questionable angioedema soon after ketoconazole was given again; thus she was considered imidazole intolerant. Four others were lost to follow-up. Among the 23 evaluable patients, 15 had AIDS, 5 had AIDS-related complex (ARC), and 3 had no symptom of HIV infection before this episode. Nine had suffered one or more episodes of oral candidiasis within the previous 6 mo.

On day 4, no patients had signs and symptoms of oral can- didiasis. The clinical response persisted in $22(96 \%)$ of 23 patients on day 7 , in $16(73 \%)$ of 22 on days $14-21$, and in $11(52 \%)$ of 21 on day $42 ; 2$ patients died from other complications of their HIV infection. A microbiologic response was documented in 20 $(87 \%)$ of 23 patients on day 7 , and persisted in $9(41 \%)$ of 22 on days 14-21 (table 1). Among the 10 patients in whom signs and symptoms recurred, the free interval after the administration of fluconazole was 6-33 d (median: $18 \mathrm{~d}$ ).

In this observation, the success rate for a single-dose treatment of oral candidiasis with fluconazole was $100 \%$ at day 4 , but signs and symptoms recurred in 10 patients during the study period. Seven had one or more episode of oral candidiasis during the previous $6 \mathrm{mo}$, and six had AIDS. However, all responded again to a second $150 \mathrm{mg}$ dose of fluconazole. The drug was well tolerated in all patients, and no hepatic, renal, or hematologic side effects were observed. Among the 23 patients, 18 were enrolled in a prospective zidovudine postmarketing surveillance program, and fluconazole did not appear to be associated with such zidovudine toxicity as granulocytopenia or anemia. As plasma drug levels were not measured, the possibility of subclinical interaction could not be excluded. The correlation between the culture and the clinical response was weak after day 7: An increasing number of $\mathrm{Can}$ dida upon semiquantitative cultures was not predictive of a clinical relapse. Culture was helpful only for the initial confirmation of the clinical diagnosis.

Single-dose fluconazole oral therapy for oropharyngeal candidiasis was easy to administer, effective, and well tolerated in our limited pilot study. This therapeutic approach might avoid continuous treatment in patients in whom advanced immunosuppression induces frequent relapses and is of special interest when ketoconazole cannot be used.

J. P. Chave, A. Cajot, J. Bille, M. P. Glauser Division of Infectious Diseases, Department of Internal Medicine and Institute of Microbiology, Centre Hospitalier Universitaire Vaudois, Lausanne, Switzerland

\section{References}

1. Warner LC, Fisher BK. Cutaneous manifestations of the acquired immunodeficiency syndrome. Int J Dermatol 1986;25:337-350

2. Kaslow RA, Phair JP, Friedman HB, Lyter D, Solomon RE, Dudley J, Polk BF, Blackwelder W. Infection with the human immunodeficiency virus: clinical manifestations and their relationship to immune deficiency. Ann Intern Med 1987;107:474-480

3. Tabor E. Hepatotoxicity of ketoconazole in men and in patients under 50. N Engl J Med 1987;316:1606-1607

4. Saag MS, Dismukes WE. Azole antifungal agents: emphasis on new triazoles. Antimicrob Agents Chemother 1988;32:1-8

5. Farrow PR, Brammer KW, Feczko JM. Fluconazole: a new treatment for oropharyngeal candidiasis in AIDS and malignancy [abstract 949] In: Program and abstracts of the 27th Interscience Conference on Antimicrobial Agents and Chemotherapy. New York: American Society for Microbiology, 1987 